DOI https://doi.org/10.30525/978-9934-26-019-3-9

\title{
A CONTACT INTERACTION OF ELEMENTS IN CONSTRUCTION BY THE MATCHED SURFACES: MODELS, ALGORITHMS, RESULTS OF RESEARCH
}

\section{Tkachuk N. A., Ischenko O. A.}

\section{INTRODUCTION}

A significant amount of machine building structures consists of elements, which are in contact with each other on the matched surfaces. Specific features of the contact pressure distribution and the areas of elastic solids contact are substantiated in certain cases. It is because, the shape and the size of the contact areas under a non-zero load do not depend on its level. Additionally, the contact pressure law also does not depend on the load, and the pressure quantity is directly proportional to ones.

These features make it possible to scale up problem solving in solids contact interaction with the matched contact surfaces despite the nonlinearity of this task in generally. They make study quicker at the design stage, and analytical accuracy acceptable for the contact interaction and the stress-strain state of elements in construction, which are being designed or modified.

However, the patterns of solids contact interaction with the matched surfaces are without undoing the need to solve at least a single-one task of analysis for a particular case. In addition, there are related discrepancies in numerical calculation models and methods for studying solids contact interaction. So, it is recommended to solve several tasks by varying load levels to confirm the validity of the results.

In particular, the studies in the same way were carried out on the example of dies tooling elements. The systems of interactions between such solids as "male die part - plate material - matrix" and "upper base plates - interchangeable pack - lower base plates - bolster press plate" were considered. They are subsystems in the system of cold-forming of sheet metals. In their design, the size and shape of the contact areas, contact pressure levels, stresses and displacements are of interest. The Variational Inequality Theory, the finite element method and the parametric modelling were used. By means of them, dependences of 
these values on the stamping force level, that affects the systems under study, were established. Along with, their directly proportional with this variable force were confirmed.

Johnson's monograph [5] can be considered as a starting publication for the analysis of existing models and methods for studying the elastic solids contact interaction. Basic methods and models for studying solids contact interaction are described in the monograph. In particular, it was noted that in case of solids contact with the matched surfaces, the pressure distribution remains constant and its value is proportional to the level of acting forces. However, only general models and methods for solving contact interaction tasks are described in this monograph. At the same time, practice requires clear solutions with numerical results for specific tasks.

More targeted tasks of contact interaction are contained in the works A. S. Kravchuk [1, 2], R. M. Martynyak [3, 8, 9], Kalker J. J. [5, 7], E. Vollebregt $[13,14]$. They are based on the Variational Inequality Theory, and the 'minimum-energy' theory. Tasks are formed as a search for the minimum or full internal energy on kinematically admissible displacement fields $[1-3,8,9]$ or additional energy on integral contact pressure distributions [5-7, 13, 14]. A number of tasks have been solved, but it is impossible to apply the results directly to other structures.

We can consider the task statements, given in [10-12], as a development of existing models and methods. These statements combine the parametric modelling method, the finite element method and boundary-element method. As a result, it is possible to adapt the studies to different types of structures with contacting solids. At the same time, due to the parametric description there are no fundamental obstacles to the variation of the structure, shape, parameters and properties of the materials of the contacting solids. In addition, the competitive advantages of co-boundary and finite element statements make it possible to choose a more effective and appropriate solution for every particular case.

The problem about system of solids contact interaction with the agreed surfaces are proposed, based on the considerations about develop the approaches given in the works [4, 10-12].

The Aim of the study is to develop approaches, models and methods of analysis the stress-strain state of elements in construction at the process of contact interaction with the matched contact surfaces.

The Research Object is the stress-strain state of elements in construction, at the process of contact interaction with the matched contact surfaces. 
The Subject of research is impact patterns of contact interaction of elements in construction on their stress-strain state based on shearing die elements.

Research hypotheses:

1. Materials of the solids under study work in the elastic field.

2. Friction in the solids contact area may be neglected.

3 . The geometrically linear statement is valid.

\section{Methods}

Without loss of generality, let's consider the task on the example of analysis of the stress-strain state (SSS) of dies tooling elements (DTE). These elements have all the features of the system under study (Fig. 1), including - multiple (i.e. multiple - on many surfaces) contact along flat sections of surfaces.

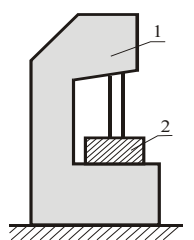

a)

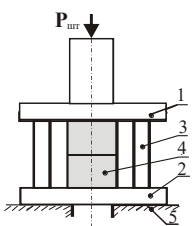

b)

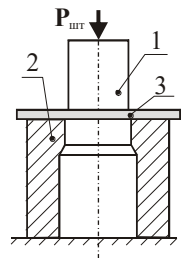

c)

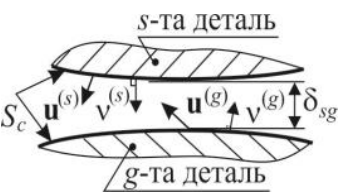

d)

Fig. 1. The die tooling elements in interaction with one another: a) press 1 and die 2; b) upper and lower base plates of die 1 i 2 , columns 3 , pack 4 and press sub-plate 5; c) male die part 1, matrix 2 and pressed metal 3; d) general scheme of construction parts contact interaction

Following [12], it can be noted that in general. the task of studying the strength, resistance, stiffness accuracy properties of an DTE results into a system of differential equations that form the initial-boundary value problem. The system of resolving correlations can be presented optionally:

$$
L(u, \sigma, p, f, t)=0 \mathrm{~L}(\mathrm{u}, \sigma, \mathrm{f}, \mathrm{t})=0 \mathrm{~L}(\mathrm{u}, \sigma, \mathrm{f}, \mathrm{t})=0,
$$

where $L-$ the initial-boundary value problem statement, $u, \sigma-$ displacement vector and stress tensor of dies tooling elements, $t$ - array of external loads set by the stamp efforts $P_{\text {шт }}, t$ - time, $p$ - array of 
generalized parameters: they are the ones that determine the variability of the geometric shape, size, and properties of the DTE material, due to them various studies can be carried out to justify the rational parameters of DTE, in this case - shearing die (SD).

In a detailed form, the ratios for determining SSS DTE looks like:

$$
\varepsilon_{i j}=1 / 2\left(u_{i . j}+u_{j . i}\right), \sigma_{i j, j}+F_{i}=0, \sigma_{i j}=C_{i j k l} \varepsilon_{k l}
$$

where ${ }^{*}{ }_{\mathrm{i}}=\partial * / \partial \mathrm{x}_{\mathrm{i}}-$ derivative with respect to $\mathrm{x}_{\mathrm{i}}, \quad r=\left\{x_{1}, x_{2}, x_{3}\right\}^{\mathrm{T}}-$ position vector of points formed by a set of Cartesian coordinates $x_{1}, x_{2}, x_{3} ; u_{i}, \varepsilon_{i j} \sigma_{i j}$ - components of point displacement vector of the object under study, strain tensor and stress tensor respectively, $C_{i j k l}-$ elastic modulus tensor of materials, that the elements under study consist of, $F_{i}-$ component of volume load; indexes $i, j, k, 1=1,2,3$ (when they are repeated in an expression, the summation rule for this index applies).

In contrast to the classical ones, boundary conditions apply on surfaces $S_{C}$ (with numbers $s$ and $g$ ) of possible contact with gaps $\delta_{s g}$, that mean not the penetration of solids into each other:

$$
\left.\left(u_{i}^{(s)} n_{i}^{(s)}+u_{k}^{(g)} n_{k}^{(g)}\right)\right|_{s_{C}} \leq \delta_{s g},
$$

Where $u, n$-components of displacements and normals respectively (see Fig. 1).

These conditions, unlike traditional ones, have the form of inequalities. This immediately makes the problem a non-linear one. It is necessary to determine both the contact area and the contact pressure during problem solving

$$
q=\left.q(r)\right|_{S_{c}} \geq 0
$$

This is the main difficulty in solving it. The feature of DTE is the presence of no-single but multiple contact on matched surfaces, in particular on flat surfaces. Than $\delta_{s g} \equiv 0 \quad \forall s, g$. We come to operate with a large array of complex tasks because of the non-linearity of the task (1) - (4) and the variability of technical solutions of dies. Accordingly, time requirements and computing resources are increasing 
dramatically. At the same time, these studies should be done rapidly. As a result, we encounter a central contradiction of the methodological plan.

Appropriate theoretical developments have been made to resolve this contradiction. They relate to the trend of changing the solution of the variational problem. Indeed, from the solution of the problem of minimizing the total internal energy functional $[1,2]$

$$
I(v)=\frac{1}{2} \sum_{s} \int_{\left(\Omega_{s}\right)} \sigma_{i j}^{(s)} \cdot \varepsilon_{i j}^{(s)} d \Omega-\sum_{s} \int_{\left(S_{\sigma}^{(s)}\right)} \sigma_{i}^{\wedge} u_{i} d S-\sum_{s} \int_{\left(S_{C}\right)} \sigma_{s j} \cdot v_{j} \cdot u_{s} d S
$$

by collection of elements

$$
K \in\left\{v^{(s)}:\left.\left(v_{i}^{(s)} n_{i}^{(s)}+v_{k}^{(g)} n_{k}^{(g)}\right)\right|_{S_{s g}} \leq 0\right\},
$$

that is set by linear restriction (3) from $\delta_{s g} \equiv 0$, we can come to the following conclusion: if an absolute minimum is reached for some parameter, than there is a shift according to the stamping force; if it is restricted by some parameters, there is an offset from the original value by the same amount in this area (Fig. 2). In other words, the position of the conditional and unconditional minimum linearly depend on the load.

It was found that, the contact area does not change in case of increasing stamping force; the contact pressure law remains stable, and components of SSS is directly proportional to ones. This result makes it possible to drastically reduce the volume of numerical studies by reducing the options for analyzing SSS of die elements or other similar constructions with multiple contacts of individual solids with matched contact surfaces.

The developed complex model was implemented in a software as a specialized program-model complex (SPMC). It combines, on the one hand, special modules, and on the other, universal packages of the SolidWorks type, and Creo (parametric and geometric models were created there), and in ANSYS - finite-element models (FEM) of DTE. This made it possible to move on to applied problem solving, described below.

\section{Results}

Tasks of contact interaction between die tooling elements in the variety of the problem statements were solving. (Fig. 3). 
1. Contact interaction between individual elements of shearing die.

The influence of the lower base plate thickness and the failure diameter holes in the press plate die on the contact pressure, stresses and displacement was investigated.

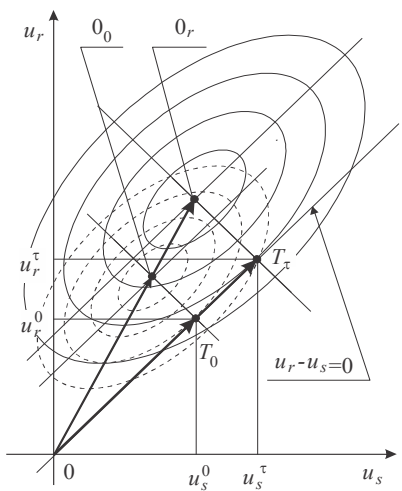

Fig. 2. Level lines of function $I$ in the section $u_{r}-u_{s}$

It was made the established regularities (Fig. 4, 5): the stresses in the elements of this subsystem are concentrated in the areas of their mechanical contact; the stresses and contact pressure are distributed unevenly over the areas of the contact joint; the integral dependences of the SSS characteristics, such as base plate thickness and failure diameter holes, on the varied parameters correspond to hyperbolic behavior (Fig. 7, fast growth when the material volume of a detail falls below a certain limit, a practically constant value during the growth of this volume above some other boundary, and a smooth change in the transition range).

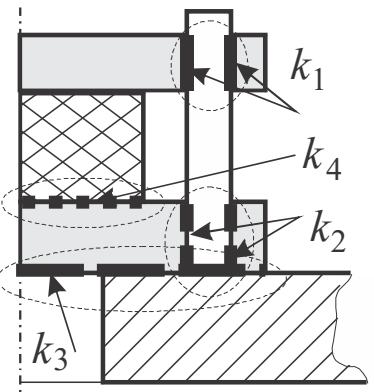

Fig. 3. Elements of the technological system under study and corresponding characteristic zones of contact interaction $k_{1} \div k_{4}$ 

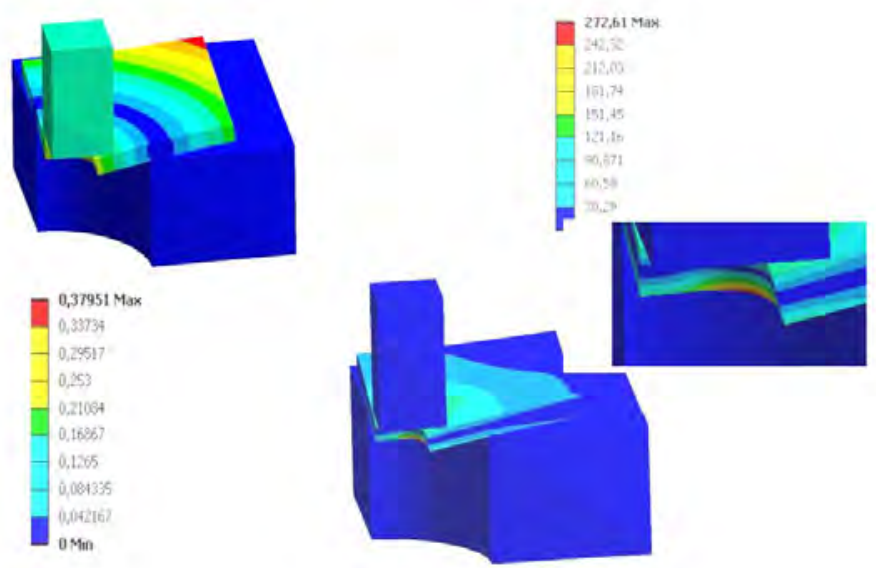

a)

б)

Fig. 4. Results of the SSS study of die elements: a) the distribution of complete displacements; b) equivalent (von Mises) stresses in the base plate, MPa (1/4), $P_{\text {шт }}=100 \kappa H$
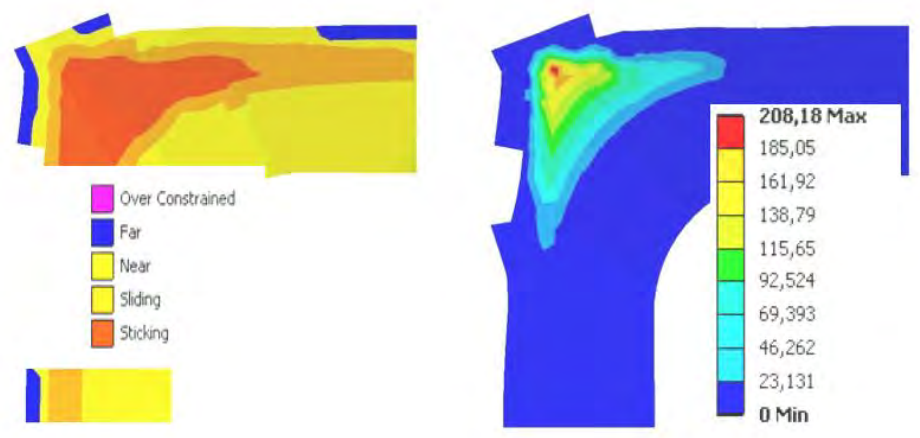

contact areas

contact pressure

Fig. 5. Results of the SSS study of die elements in the interchangeable pack and base plate, $P_{\text {шт }}=100 \mathrm{\kappa H}$ 

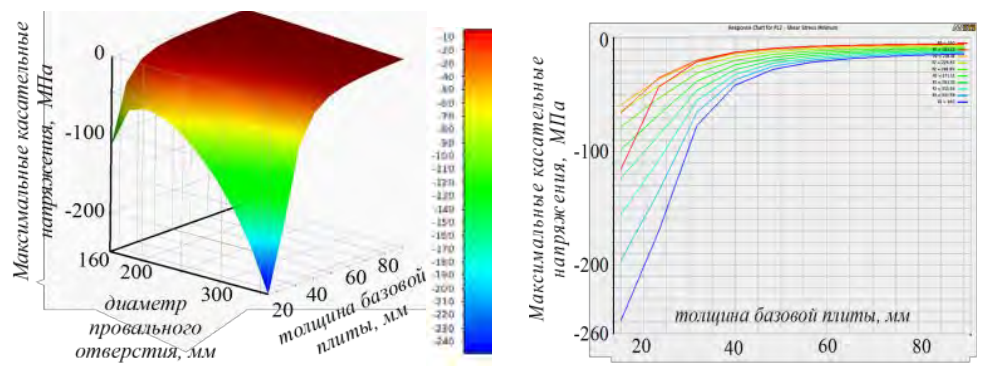

Fig. 6. Dependence of the maximum tangential stresses on the thickness of the lower base plate and the diameter of the falling hole

2. Contact interaction of elements of assembly dies.

A more detailed model of the stress-strain state of the block of separation dies made it possible to investigate the complete behavior of the assembly dies. (Fig. 8). The obtained results show that the SSS of this subsystem has the same features that were installed on fractional models. It can be seen that the established patterns (Fig. 9), namely regarding the substantially uneven distribution of contact pressure in the interactions of die tooling elements, are confirmed with the error of up to $5 \%$.

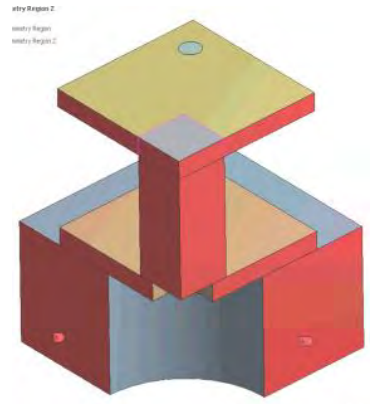

Fig. 7. Geometric model of the SS

The same can be said about the distribution of complete displacements, von Mises stresses (Fig. 9-12). From the whole system, it is possible to separate SSS patterns of separate elements. These patterns also give grounds for confirming the predicted features of the SSS, based on partial models: about stress concentration in the zones of contact interaction of individual die elements and significant levels of elastic displacement. 

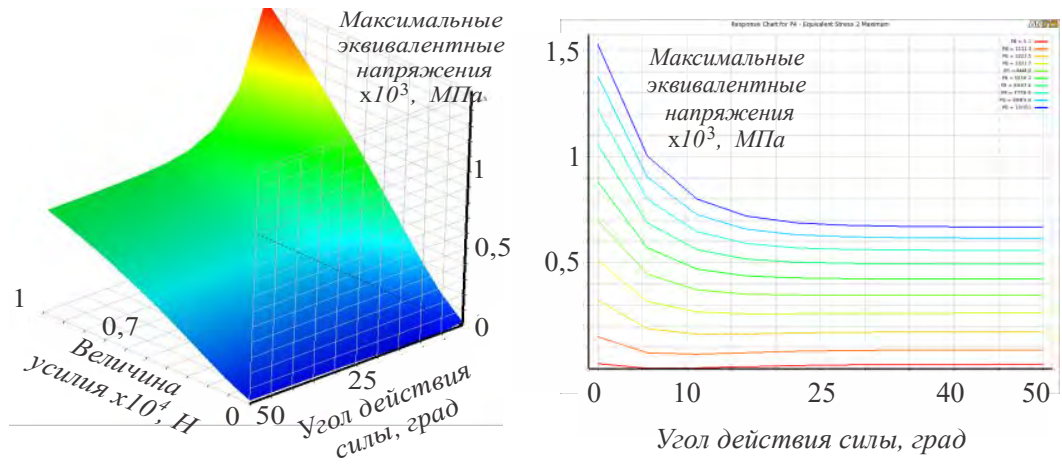

Fig. 8. Dependence of the maximum equivalent stress on the parameters $p_{1}, p_{2}$ (the angle of action and the intensity of stress, respectively)

In Fig. 13 shows the results obtained regarding the effect of stamping forces on contact pressure. With satisfactory accuracy for practice, the linear dependence of the contact pressure on the stamping forces is determined with the error of up to $2 \div 5 \%$.

In Fig. 14 show the dependences of deflections, pressure and stress on the lower shoe thickness and failure diameter holes. It can be seen that the design and technological factors have a significant impact on rigidity and strength characteristics of DTE.

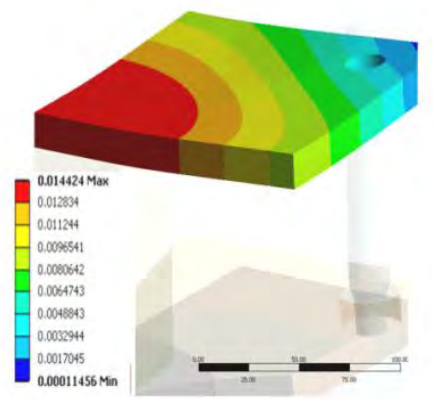

complete displacements

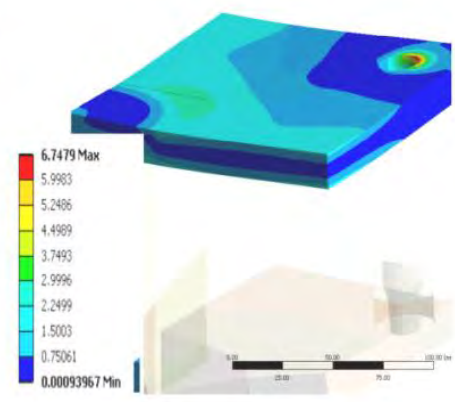

von Mises stress

Fig. 9. Distribution patterns of SSS components in the upper base plate, $P_{\mathrm{IIT}}=10 \mathrm{kN}$ 


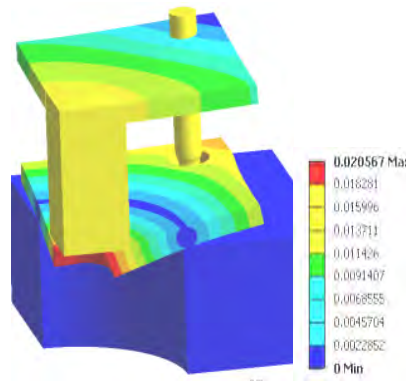

complete displacements

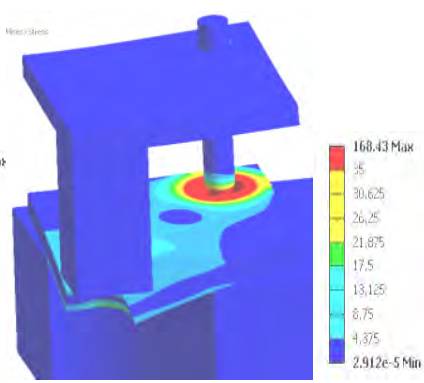

von Mises stresses

Fig. 10. Distribution patterns of SSS, $P_{\mathrm{IIT}}=10 \mathrm{kN}$

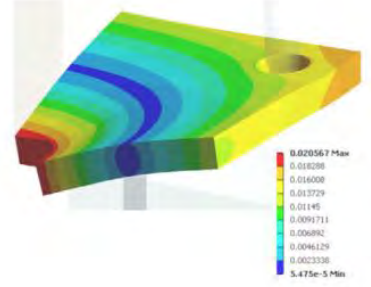

complete displacements

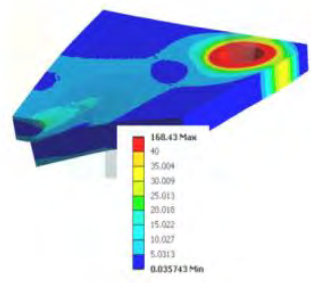

von Mises stress

Fig. 11. Distribution patterns of SSS components in the lower base plate,

$$
P_{\mathrm{IIT}}=10 \mathrm{kN}
$$
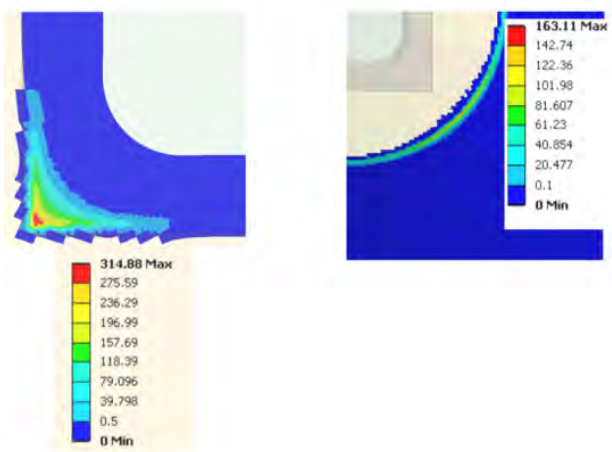

Fig. 12. Distribution patterns of contact pressure in the zones $\boldsymbol{k}_{4}, \boldsymbol{k}_{3}$,

$$
P_{\mathrm{IIT}}=100 \mathrm{kN} \text { (see Fig. 4) }
$$




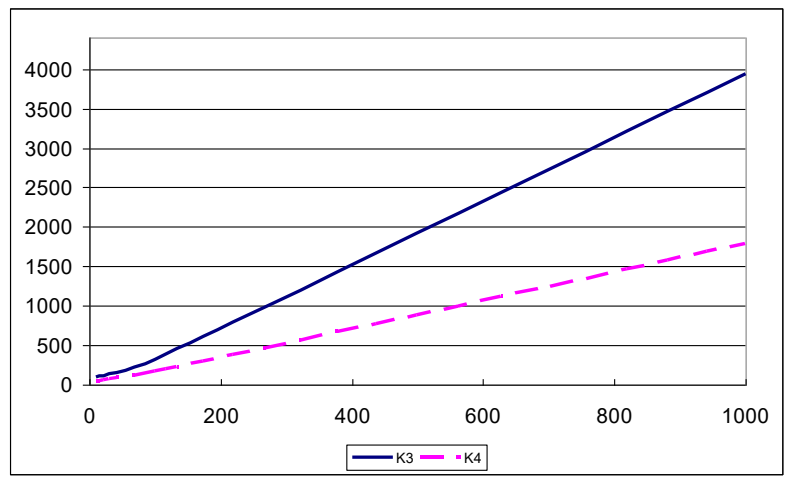

Fig. 13. Dependence of the maximal contact pressure (Mpa) in the joints, $k_{3}, k_{4}$, on the amount of the stamping forces $(\mathrm{kN})$

Thus, we can conclude that a qualitative distribution pattern of the SSS components can be analysed by the results of studying a more complete die model. At the same time, the quantitative dependencies of the SSS characteristics on the variable parameters can be determined by the calculation results using of partial models, which are less cumbersome. This means that they require the less computational cost for computer modelling. As a result, a balance between the accuracy of the results obtained and complexity of the developed models is ensured.

3. Contact interaction in the system "male die part - plate material-matrix".

We come to the analysis of DTE be refer to the study of SSS "lower" level models, also taking into account contact interaction of male die part and matrix with plate material (see Fig. 1). The cutting elements (male die parts, matrices, male die part-matrices) in interaction with the stamped material are the most accountable in terms of tension.

Parametric models of the system under study presented in Fig. 15. The SSS of this system for the axisymmetric case at the elastic deformation stage is investigated.

In Fig. 16, 17 the patterns of the deformed statement of the system under study and the characteristic contact pressure distribution in the cutting edge zone are presented. In Fig. 18 is shown how changing the contact pressure distribution pattern in case of the magnitude of the stamping forces. 


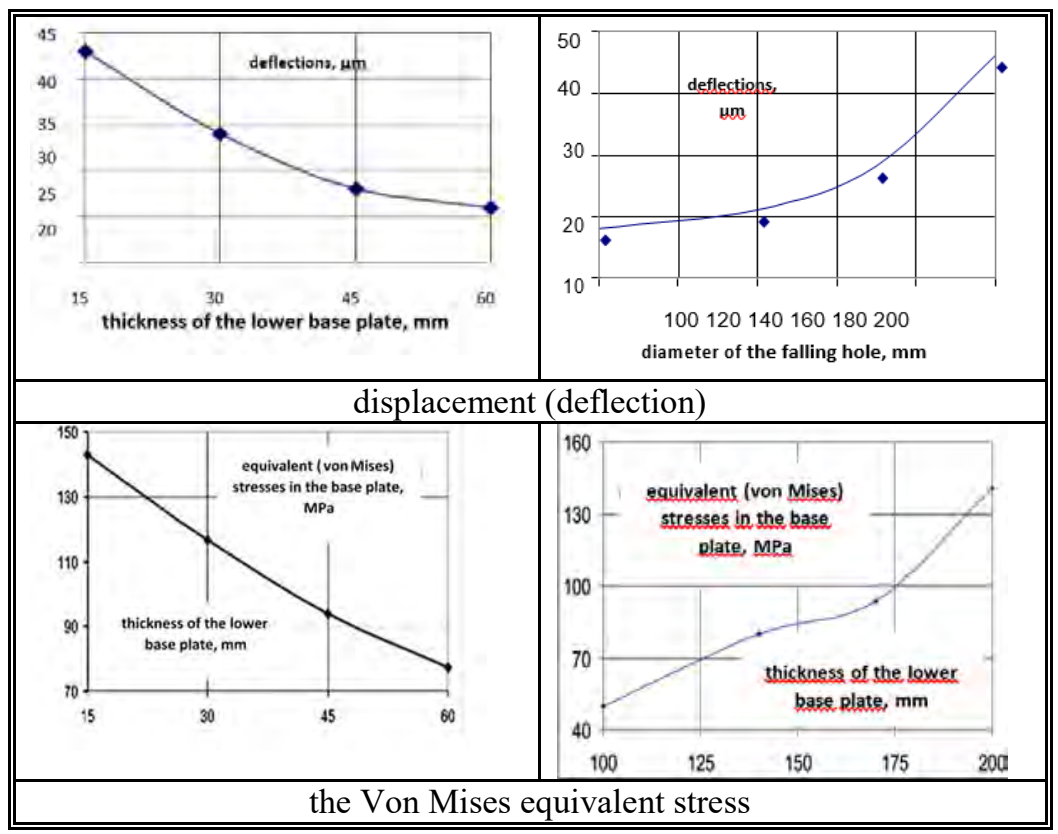

Fig. 14. The dependence of the SSS components in the base plate on the variable parameters
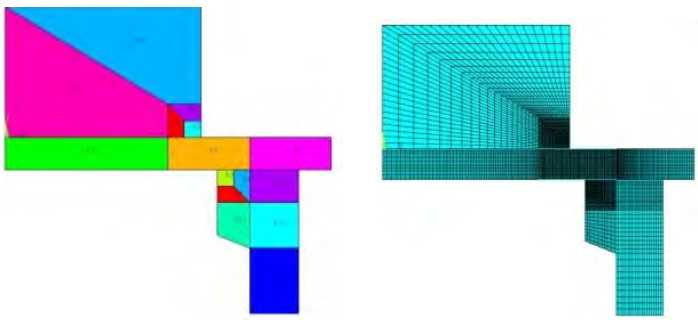

Fig. 15. Parametric geometry model and finite-element model of the system "male die part - plate material - matrix" SD (axisymmetric case)

The results of the study the stress-strain state of the system under study and contact pressure distribution in variation of loads demonstrate that the contact area are practically independent on level of applied force. In this case, the law of contact pressure distribution remains stable, and its level is proportional to the stamping forces. 

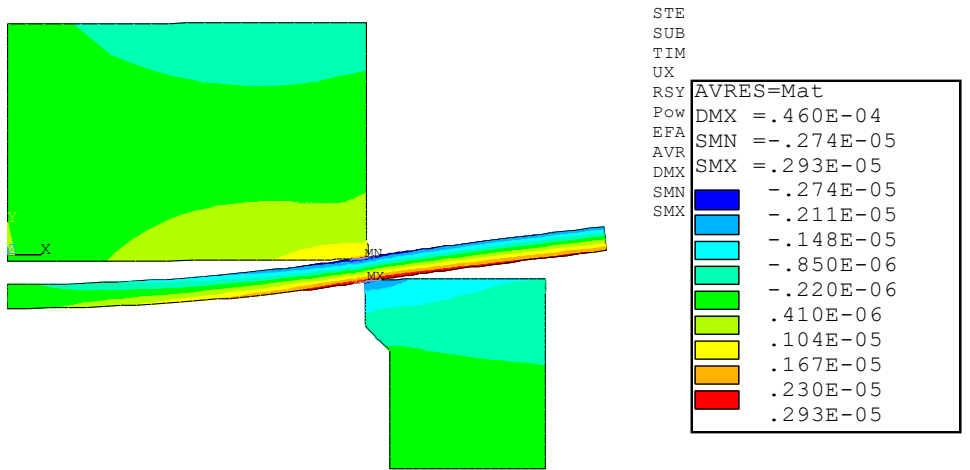

Fig. 16. Distribution radial elastic displacement (m) in the system under study

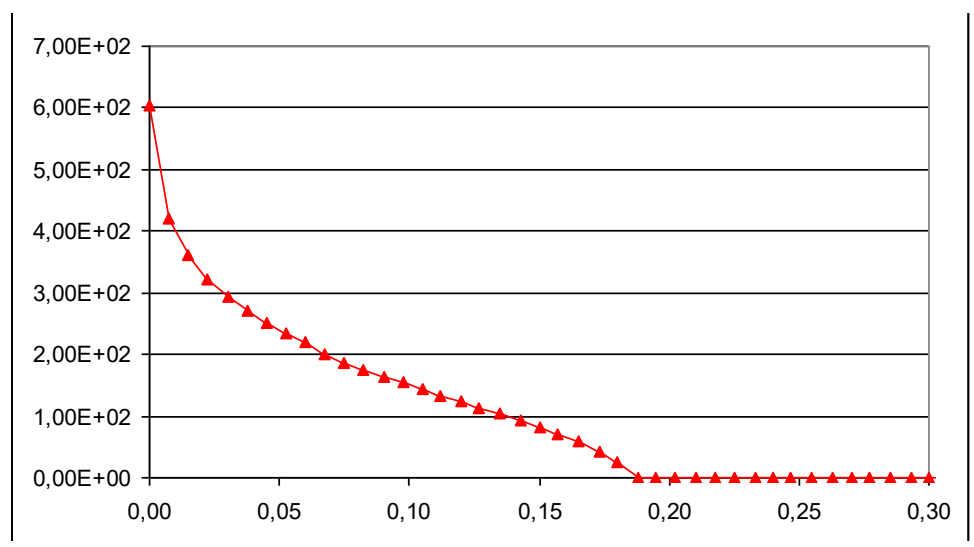

Fig. 17. Features of contact pressure (Mpa) in the cutting edge zone along radial coordinate $(\mathrm{mm})$

Thus, the basic patterns in similar contacting options for elastic solids are confirmed in the course of studying the SSS of the "male die part plate material - matrix" system of SD. 


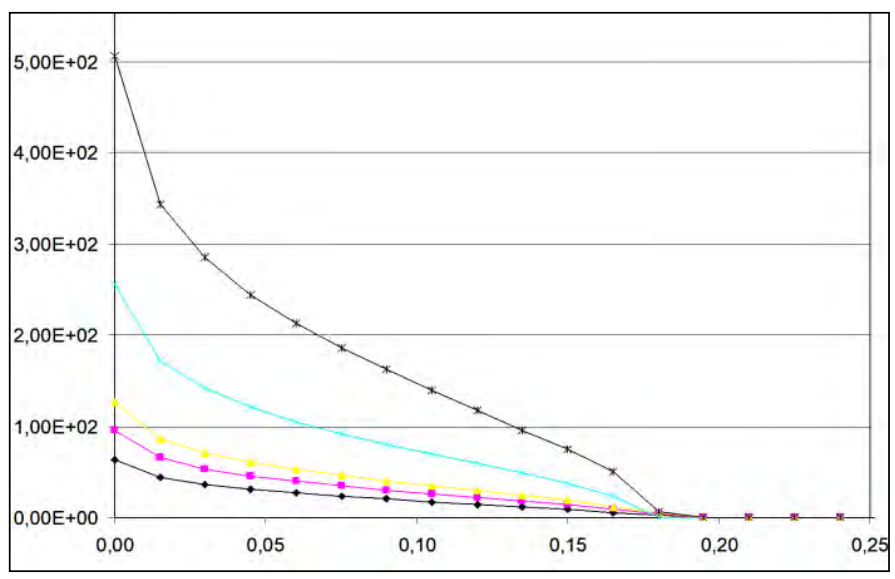

Fig. 18. Dependence of the contact pressure (Mpa) on the magnitude of the stamping forces $(\mathrm{H})$ in the cutting edge zone along radial coordinate $(\mathrm{mm})$

\section{Discussion}

1. The problem about the stress-strain state and the multiple contact interaction of solids systems with the matched surfaces was set and solved on the example of dies tooling elements. Parametric models of the objects under study were formed. The variational principles of the theory of variational inequalities and discretisation based on the finite element method were applied. This made possible to define of the stress-strain state by a quadratic programming problem with homogeneous linear constraints of the inequality type.

2. The features of solving analysis tasks of the stress-strain state of a solids system were confirmed. Also it was taking into account their contact interaction with the matched surfaces. Features were predicted based on the problem solving behavior of minimizing an energy functional on a set of linear one-sided constraints, describing the contact conditions. In particular, the invariance of the contact area from the level of acting forces was confirmed, as well as proportionality of contact pressure to external forces (as well as a component of the stress-strain state of the elastic solids system, which are in contact). At the same time, the confirmation was true for models of different coverage levels of the solid system - from a more general and enlarged to a more detailed one.

3. The developed complex mathematical model was implemented in software as specialized program-model complex. Such property differed the complex from the traditional computer modelling. It provided an opportunity 
for solving both single analysis tasks and entire series of ones in an automated mode. In addition, it was also possible to complicate the level of computational models (to "build-up" the composition and structure) sequentially. This opportunity was not available in traditional software packages. This made it possible to analyze the degree of reliability and the scope of regularities established on the base of the lower-level models: namely, a high degree of reliability and a wide range of applications were provided in the case of qualitative and quantitative origin of the calculation results while using the upper-level model. Otherwise, the cycle of models complication was repeated.

Developed approaches, models, methods and results of the study are the initial ones for their generalization and extension on cases of perturbation of the solids contacting form and implementation between them intermediate layers with different material properties.

\section{CONCLUSIONS}

The complex mathematical model has been developed for studying the stress-strain state of elastic solid, which are in contact with each other on the matched surfaces. The model based on dies tooling elements. This differed the model from the mathematical models that already exist and made it possible to take into account the multiple contact interaction between elements of investigated systems. In addition, the model was integrated with the technology of parametric modelling that enables to solve synthesis tasks with more reliable non-linear analysis tasks.

Features of the contact pressure distribution and the areas of elastic solids contact, which contact with the matched surfaces, were investigated. It was found that, the shape and the size of the contact area under non-zero load do not depend on its level. The contact pressure law also does not depend on the load level. In addition, the contact pressure is directly proportional to them. The contact interactions between dies tooling elements "male die part - plate material - matrix" and "upper base plates - interchangeable pack - lower base plates bolster press plate" were researched to confirm the validity of the results.

\section{SUMMARY}

A significant amount of machine building structures consists of elements, which are in contact with each other on the matched surfaces. Specific features of the contact pressure distribution and the areas of elastic solids contact are substantiated in certain cases. It is because, the shape and the size of the contact areas under a non-zero load do not depend on its level. 
Additionally, the contact pressure law also does not depend on the load, and the pressure quantity is directly proportional to ones.

These features make it possible to scale up problem solving in solids contact interaction with the matched contact surfaces despite the nonlinearity of this task in generally. They make study quicker at the design stage, and analytical accuracy acceptable for the contact interaction and the stress-strain state of elements in construction, which are being designed or modified.

The Aim of the study is to develop approaches, models and methods of analysis the stress-strain state of elements in construction at the process of contact interaction with the matched contact surfaces.

The Research Object is the stress-strain state of elements in construction, at the process of contact interaction with the matched contact surfaces.

The Subject of research is impact patterns of contact interaction of elements in construction on their stress-strain state based on shearing die elements.

\section{REFERENCES}

1. Kravchuk A. C. K zadache Gertsa dlya lineyno- i nelineynouprugih tel konechnyih razmerov. Prikladnaya matematika i mehanika. 1977. Tom 41. P. 329-337. (in Russian).

2. Kravchuk A. C. Metod variatsionnyih neravenstv v kontaktnyih zadachah. Mehanika kontaktnyih vzaemodeystviy. 2001. P. 93-115. (in Russian).

3. Martinyak P. M. Kontakt pruzhnih til za nayavnosti neliniynih Vinklerivskih poverhnevih sharIv. Matematichni metodi ta fizikomehanichni polya. 2013. T. 56, № 3. P. 43-56. (in Russian).

4. Atroshenko O., Tkachuk M., Martynenko O., Tkachuk M., Saverska M., Hrechka I., Khovanskyi S. The study of multicomponent loading effect on thin-walled structures with bolted connections. EasternEuropean Journal of Enterprise Technologies. 2019. № 1/7 (97). P. $15-25$.

5. Johnson K. L. Contact Mechanics. Cambridge University Press. 1985. 462 p. doi:10.1017/cbo9781139171731.

6. Johnson K. L., Knothe K. (2008). "Joost J. Kalker (1933-2006) living with rolling contact". Vehicle System Dynamics. 46 (1-2): 5-7.

7. Kalker J. J. Variational principles of contact elastostatics. J. Inst. Math. and Appl. 1977. Vol. 20. P. 199-221. 
8. Kozachok O. P., Slobodian B. S., Martynyak R. M. Interaction of Two Elastic Bodies in the Presence of Periodically Located Gaps Filled with a Real Gas. Journal of Mathematical Sciences. 2017. No. 222(2). P. 131-142.

9. Slobodyan B. S., [...], Martynyak R. M. Modeling of Contact Interaction of Periodically Textured Bodies with Regard for Frictional Slip. Journal of Mathematical Sciences. 2016. Vol. 215(1). P. 110-112.

10. Tkachuk M. A. Numerical method for axisymmetric adhesive contact based on Kalker's variational principle. Eastern-European Journal of Enterprise Technologies. 2018. Vol. 3, Issue 7 (93). P. 34-41.

11. Tkachuk M. M., Skripchenko N., Tkachuk M. A., Grabovskiy A. Numerical Methods for Contact Analysis of Complex-Shaped Bodies with Account for Non-Linear Interface Layers. Eastern-European Journal of Enterprise Technologies. 2018. Vol. 5/7 (95). P. 22-31.

12. Tkachuk M. M., Grabovskiy A., Tkachuk M. A., Hrechka I., Ishchenko O., Domina N. (2019) Investigation of multiple contact interaction of elements of dividing stamps. Eastern-European Journal of Enterprise Technologies, 4/7 (100), 6-15.

13. Vollebregt E., Segal G. Solving conformal wheel-rail rolling contact problems. Vehicle System Dynamics. 2014. Vol. 52. P. 455-468.

14.Zhao J., Vollebregt E., Oosterlee C. Extending the BEM for elastic contact problems beyond the half-space approach. Mathematical Modelling and Analysis. 2016. Vol. 21(1). P. 119-141.

\section{Information about the authors:} Tkachuk N. A.,

D. Sci. (Engineering), Head of the Chair for Theory and Computer-Aided Design of Mechanisms and Machines, National Technical University "Kharkiv Polytechnic Institute" 21, Kirpicheva str., Kharkiv, 61002, Ukraine

Ischenko O. A., Cand. Sci. (Engineering), Senior Lecturer at the Department of Mathematics and Physics, Dmytro Motornyi Tavria State Agrotechnological University 18, B.Khmelnytsky ave., Melitopol, Zaporizhzhia region, 72312, Ukraine 